\title{
EFFECT OF PHOSPHORUS CONTENT AND COLD DEFORMATION ON MECHANICAL PROPERTIES OF CUAg0.1 ALLOY
}

\author{
Aleattin KULAKLI, Talip ÇITRAK, Serdar TOZKOPARAN, Aydın Barış ŞıMŞIR, Edanur KASAP \\ Sağlam Metal San. ve Tic. A.Ş., Kocaeli, Turkey, \\ aleattin.kulakli@saglammetal.com, talip.citrak@saglammetal.com, serdar.tozkoparan@saglammetal.com, \\ arge@saglammetal.com, edanur.kasap@saglammetal.com
}

https://doi.org/10.37904/metal.2021.4226

\begin{abstract}
Copper-silver alloys are preferred alloys when it is desired to maintain the electrical conductivity and mechanical strength values at room temperature, at high temperatures, and where it is necessary to have higher creep strength and softening temperature than ordinary copper alloys. In this study, the effect of phosphorus content and cold deformation ratio were investigated on the mechanical properties and electrical conductivity of a copper-silver alloy which is called CuAg0.1 (CW016A). Microstructure of the alloys were examined by light optic microscope (LOM) and scanning electron microscopy (SEM). When the phosphorus content of the alloy exceeded the limit value given in the standards, the electrical conductivity value decreased below the standard value, while the hardness increased.
\end{abstract}

Keywords: Copper silver alloy, hot forging, cold forging, microstructure

\section{INTRODUCTION}

Copper-silver alloys are preferred alloys when it is required to maintain the electrical conductivity and mechanical strength values at room temperature or at high temperatures, and where the creep strength and softening temperature are required to be higher than ordinary copper alloys. Electrolytic refined copper, oxygen-free and deoxidized copper can be produced with silver additions up to $0.12 \mathrm{wt} \%$. The addition of silver is to increase the resistance to softening without significantly affecting the electrical conductivity [1]. Low levels of phosphorus additions ( $\sim-1 \mathrm{wt} \%)$ do not change the deformation structure or texture of pure copper. CuAg0.1P is a silver-containing, deoxidized pure copper with a low phosphorus content. Its electrical conductivity is comparable to Cu-ETP. Unlike other pure copper types, this alloy has a higher recrystallization temperature and better creep behaviour [2,3]. The addition of $0.08-0.12$ wt\% silver provides very good creep resistance and it is suitable for use in high tensile rotor winding strips and car wires. The electrical conductivity of these alloys is $100 \%$ IACS. These alloys are included with different codes in standards such as EN, DIN, ASTM. Their minimum electrical conductivity is $98.3 \%$ IACS [4]. CuAg0.1P has a high deformation rate and very good cold formability [5]. CuAgP alloys are also used in continuous casting moulds [6].

In this paper, CW016A alloy which is one of the most widely used copper silver alloys, was studied. The highest phosphorus content allowed in the standards in this alloy is $0.007 \mathrm{wt} \%$. However, under production conditions, the phosphorus content of the alloy may exceed the upper limit values and affect the properties of the alloy. Therefore, in this study, the effects of phosphorus content on hardness and electrical conductivity were investigated by adding $0.007 \mathrm{wt} \% \mathrm{P}$ and higher concentration $0.015 \mathrm{wt} \% \mathrm{P}$, to CuAg0.1 alloy.

\section{EXPERIMENTAL PROCEDURE}

\subsection{Materials}

CuAg0.1P (CW016A) alloy was prepared in an induction furnace open to atmosphere with a capacity of $15 \mathrm{~kg}$. Pure copper was melted and pure silver and phosphorus were added in desired proportions and then poured 
into a permanent mould. After casting, its chemical composition was determined with a Hitachi Inspire the Next brand spectral analyzer (Table 1). Casting temperature was in the range of $1000-1200{ }^{\circ} \mathrm{C}$. Lithium (0.1 wt\%) was added to the melt in order to control oxygen content of the alloys and a special carbon-based flux was used as a slag remover. Phosphorus ratios were chosen as the upper limit value given in EN 13601 (0.007 wt $\%)$ and twice this value $(0.0151 \mathrm{wt} \%)$.

Table 1 Chemical composition of CuAg0.1 alloys (wt\%)

\begin{tabular}{|c|c|c|c|}
\hline & $\mathbf{C u}$ & $\mathbf{A g}$ & $\mathbf{P}$ \\
\hline 1 & 99.873 & 0.092 & $<0.002$ \\
\hline 2 & 99.858 & 0.0926 & 0.0074 \\
\hline 3 & 99.844 & 0.0929 & 0.0151 \\
\hline
\end{tabular}

\subsection{Cold deformation}

After melting and casting, the surfaces of the ingots were turned and $75 \mathrm{~mm}$ diameter ingots were obtained. The diameters of the ingots were reduced by $15 \%$ in the temperature range of $900-1000{ }^{\circ} \mathrm{C}$ by hot forming. Then, the hot forged samples were cold deformed at the rates of $10 \%$ and $70 \%$. The dimensions of the materials and applied cold deformation rates are given in Table 2.

Table 2 Dimensions of CuAg0.1 alloys and applied cold deformation rates

\begin{tabular}{|c|c|c|}
\hline Dimension after hot forming $(\mathrm{mm})$ & Deformation rate $(\%)$ & Thickness after cold forging $(\mathrm{mm})$ \\
\hline$\Phi 64 \times 20$ & 10 & 18 \\
\hline$\Phi 64 \times 33$ & 70 & 10 \\
\hline
\end{tabular}

\subsection{Characterization}

After cold deformation, the microstructure of all three alloys was examined using Nikon Eclipse MA100 light microscope and SEM-EDX analyzes were performed. Electrical conductivity values and then Vickers microhardness values were measured.

\section{EXPERIMENTAL RESULTS}

\subsection{Optical Microscope Images}

The microstructure images of $10 \%$ and $70 \%$ cold deformed CuAg0.1 alloy and CuAg0, 1 alloys with 0.007 wt $\%$ and $0.015 \mathrm{wt} \%$ phosphorus added are given below (Figure 1 and Figure 2).
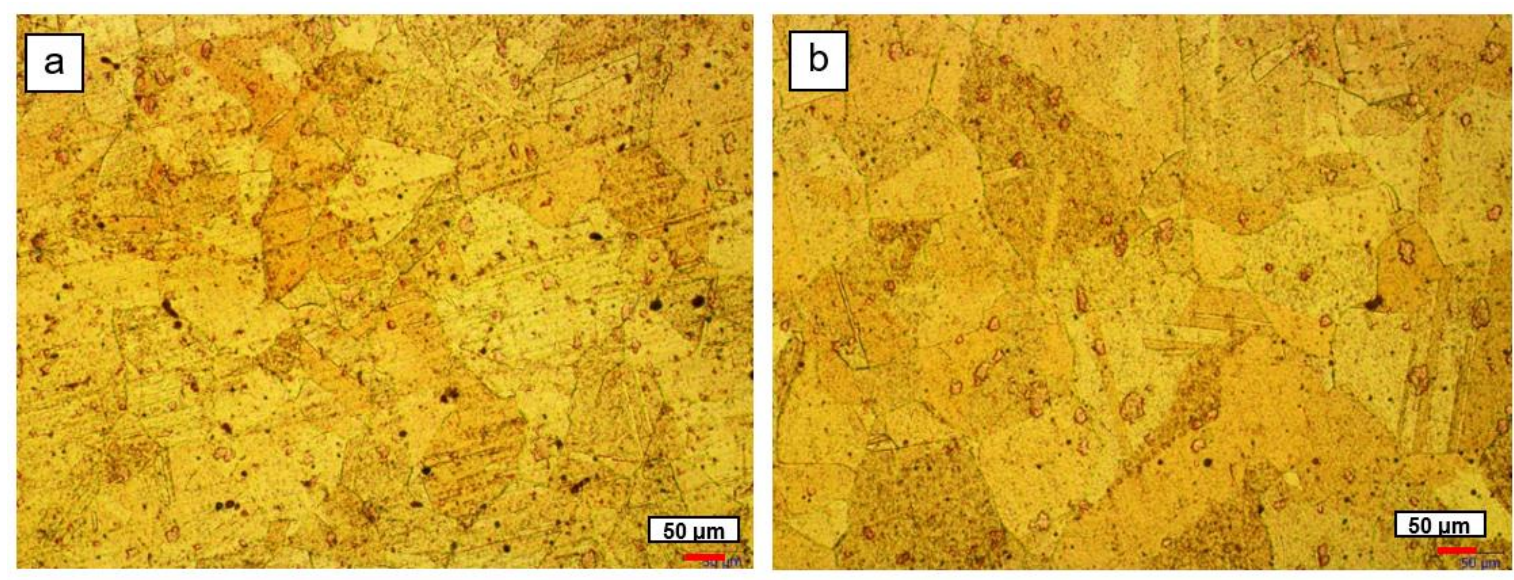


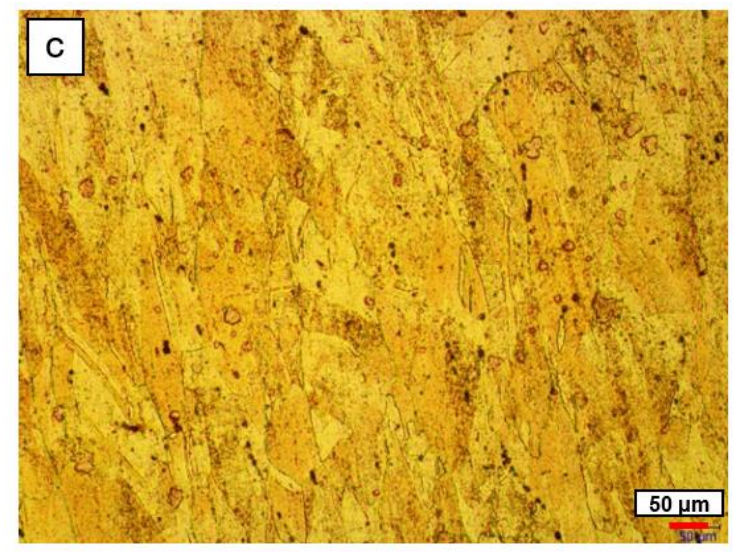

Figure 1 Microstructure of $10 \%$ cold deformed CuAg0.1 alloys a) 0 wt $\%$ P, b) 0.007 wt $\%$ P, c) 0.015 wt $\%$ P
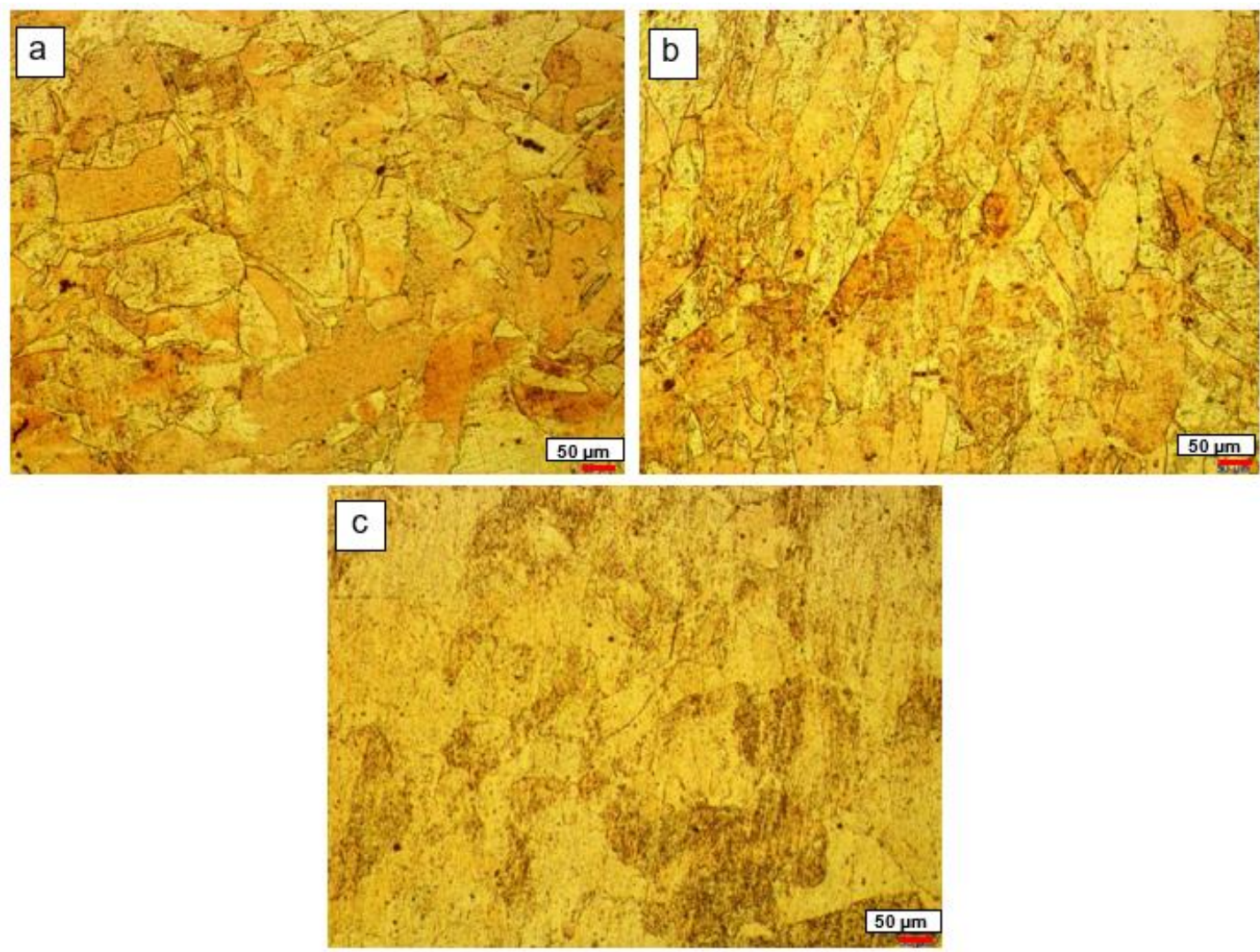

Figure 2 Microstructures of $70 \%$ cold deformed CuAg0.1 alloys a) 0 wt $\%$ P, b) $0.007 w t \% P, c) 0.015 w t \% P$

The microstructures of CuAg0.1P alloys were compared after $10 \%$ and $70 \%$ cold deformation. The images show that the grains are still distinguishable in $10 \%$ deformed samples and slightly elongate in the direction of deformation. At higher cold deformation rate the grains were more elongated as expected. On the other hand, it was observed that phosphorus addition to the alloys did not affect significantly cold deformation structure and cold deformability.

\subsection{SEM-EDS analysis}

SEM images and EDS analysis results of $10 \%$ and $70 \%$ cold deformed CuAg0.1 and CuAg0.1P0.015 alloys are given below (Figure $\mathbf{3}$ and Table $\mathbf{3}$ ). 

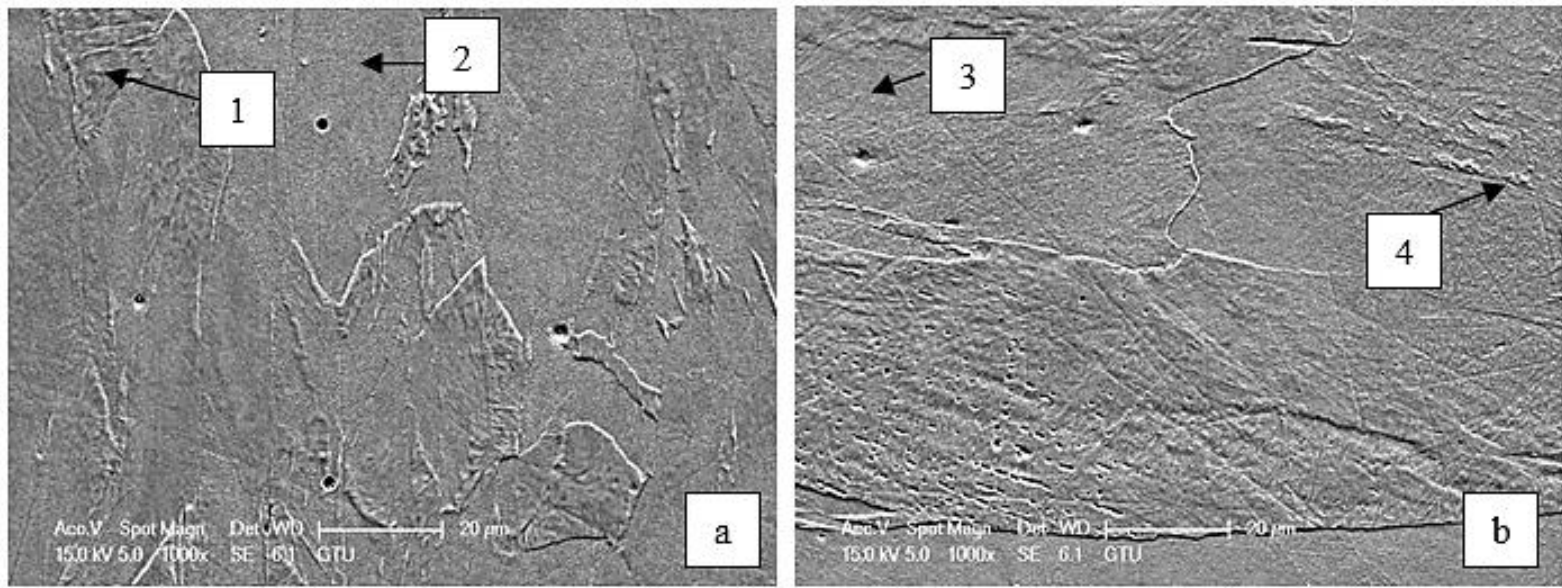

Figure 3 SEM images of $70 \%$ cold-deformed CuAg0.1 alloys a) 0 w\% P, b) $0.015 w t \% P$

Table 3 EDS analysis results (wt\%)

\begin{tabular}{|c|c|c|c|c|}
\hline Alloy & Region & Cu & Ag & P \\
\hline \multirow{2}{*}{ CuAg0.1 } & 1 & 99.51 & 0.49 & - \\
\cline { 2 - 5 } & 2 & 99.79 & 0.21 & 0.22 \\
\hline \multirow{2}{*}{ CuAg0.1P0.015 } & 3 & 99.34 & 0.44 & 0.36 \\
\cline { 2 - 5 } & 4 & 99.36 & 0.28 & \\
\hline
\end{tabular}

SEM images shows that CuAg0.1 alloy has small amount of eutectic structure marked with 1 in Figure 3a.

EDS analysis in CuAg0.1 alloy was taken from two regions of 1 (eutectic structure) and 2 (matrix). Ag content of the region of 1 is higher than that of the matrix (region 2). The same microstructure and EDS analyses were observed for CuAg0.1P0.015 except higher P content and higher ratio of eutectic phases. Most likely, some $\mathrm{Cu}-\mathrm{P}$ eutectic phases or $\mathrm{Cu}-\mathrm{Ag}-\mathrm{P}$ ternary phases may also be present in the structure.

It is possible to conclude that phosphorus forms a hard phase in the matrix by adhering to copper and increases the hardness. When Cu-P phase diagrams are examined, it is thought that it is a strong hardener due to the formation of $\mathrm{Cu}_{3} \mathrm{P}$ composition, which forms a ternary eutectoid with phosphorus, hard and $\alpha$ and $\delta$ phases [7].

\subsection{Hardness and electrical conductivity}

The electrical conductivity and hardness values of the cold forged samples at two different rates are given in Table 4. The hardness graph according to the cold deformation rate is shown in Figure 4 and the electrical conductivity graph is shown in Figure 5.

Table 4 Electrical conductivity and hardness of CuAg0.1-P alloys

\begin{tabular}{|c|c|c|c|}
\hline Alloy & Cold deformation rate (\%) & Electrical conductivity $(\mu \mathrm{S} / \mathrm{m})$ & Hardness (HV) (1000-gf) \\
\hline \multirow{2}{*}{ Cu-0.1 wt\% Ag } & 10 & 57.6 & 78 \\
\cline { 2 - 4 } & 70 & 55.8 & 106.3 \\
\hline \multirow{2}{*}{ Cu-0.1 wt\% Ag -0.007 wt\% P } & 10 & 52.1 & 80.6 \\
\hline \multirow{2}{*}{ Cu-0.1 wt\% Ag -0.015 wt\% P } & 70 & 55.6 & 113.7 \\
\cline { 2 - 4 } & 10 & 50 & 96 \\
\hline
\end{tabular}


The experimental results show that the hardness values of the $10 \%$ and $70 \%$ cold deformation applied CuAg0.1 and CuAg0.1P alloys increased depending on the deformation rate, and the conductivity values decreased slightly, as expected. According to Table 4, the highest hardness value was obtained for CuAg0.1P0.015 alloy (120.1 HV). while its conductivity value was the lowest. In the TS EN 13601 Copper and Copper Alloys standard, it is stated that the conductivity value of CuAg0.1P alloy should be above $56 \mu \mathrm{S} / \mathrm{m}$ and its hardness value should be between 90-115 HV. Accordingly, the hardness and conductivity values of the alloy containing $0.007 \mathrm{wt} \% \mathrm{P}$, which is the upper limit value given in the standard, were obtained in accordance with the standard (Table 4). However, it was determined that the hardness increased (120 HV) and the electrical conductivity decreased (from $55.2 \mu \mathrm{S} / \mathrm{m}$ to $50 \mu \mathrm{S} / \mathrm{m}$ ) slightly when the phosphorus ratio was increased to $0.015 \mathrm{wt} \%$ which is above the limit value given in the standard. The results showed that the phosphorus ratio should be carefully controlled in the production of these alloys conforming to the standard. It has been evaluated that a slightly higher amount of phosphorus $0.015 \mathrm{wt} \%$ may give good results for applications where hardness is more important and conductivity is less significant. On the other hand, the amount of phosphorus exceeding the standard value did not significantly affect the cold forgeability of the alloys. There was no cracking or defect occurred in the samples even after $70 \%$ cold forging.

\section{CONCLUSION}

The effects of phosphorus addition to the CuAg0.1 alloy at varying rates can be summarized as follows:

1) When phosphorus $0.007 \mathrm{wt} \%$ was added to the alloy at the upper limit value given in the EN 13601 standard, hardness and electrical conductivity in accordance with the standard were obtained.

2) When the phosphorus ratio increased to $0.015 \mathrm{wt} \%$, the hardness increased, while the conductivity decreased and exceeded the standard values. Accordingly, the upper limit value of the $\mathrm{P}$ amount should be carefully controlled in the production of CuAg0.1P alloy.

3) It has been observed that the increase of the phosphorus ratio above the standard value does not affect the cold forgeability.

\section{REFERENCES}

[1] TS EN 13601. Copper and copper alloys - copper rod, bar and wire for general electrical purposes. TSE, 2014.

[2] SCHLEGEL, S. Langzeitverhalten von Schraubenverbindungen mit Stromschienen aus Reinkupfer in der Elektroenergietechnik unter besonderer Berücksichtigung der Temperatur. Dresden, 2011. Dissertation. Technische Universität Dresden.

[3] HUTCHINSON, W. B., RAY, R. K. Influence of phosphorus additions on annealing behaviour of cold-worked copper. Metal Science. 1979, vol. 13, no. 3-4, pp. 125-130.

[4] CHAPMAN, D. High conductivity coppers for electrical engineering. Ed. Copper Development Association. Publication 122, 1998.

[5] CuAg0.10P. DKI, Werkstoff-Datenblatt, Deutsches Kupferinstitut, 2005.

[6] LI, G., THOMAS, B.G., STUBBINS, J.F. Modeling creep and fatigue of copper alloys. Metallurgical and Materials Transactions A. 2000, vol. 31, no. 10, pp. 2491-2502.

[7] LI, Y.N., WANG, C. W., PENG, Z.L., YAN, J.C., LIU, X.S. Dissolution behavior of Cu in Cu-Ag and Cu-P brazing alloys using weld brazing. Transactions of Nonferrous Metals Society of China. 2011, vol. 21, pp. 394-399.

[8] Innovations. Phosphor Bronze: Teaching an Old Dog New Tricks. [online]. Copper Development Association Inc. Available from: https://www.copper.org/publications/newsletters/innovations/2001/06/phosphor bronze.html. 